\title{
Biodiversity Conservation: A Preventive Tool for Epidemics and Pandemics
}

\author{
Ritesh Joshi ${ }^{1}$, Kanchan Puri ${ }^{2 *}$ \\ ${ }^{1}$ Conservation and Survey Division, Ministry of Environment, Forest \& Climate Change, New Delhi, INDIA \\ ${ }^{2}$ Development Monitoring and Evaluation Office, Niti Aayog, New Delhi, INDIA \\ *Corresponding Author: genetics_1407@yahoo.co.in
}

Citation: Joshi, R. and Puri, K. (2022). Biodiversity Conservation: A Preventive Tool for Epidemics and Pandemics. European Journal of Environment and Public Health, 6(1), em0094. https://doi.org/10.21601/ejeph/11497

ARTICLE INFO

Received: 14 Aug. 2021

Accepted: 18 Nov. 2021

\begin{abstract}
Intergovernmental Science-Policy Platform on Biodiversity and Ecosystem Services highlights that there is a close nexus between the global health pandemics and the biodiversity. The COVID-19 pandemic has clearly indicated the importance of environmental health. Seeing the advancement of scientific field, it is clear that there is some link between the biodiversity and spread of outbreaks of epidemics and pandemics. Interestingly, preservation of biodiversity has been recognized as an important step to control the disease outbreaks since last one year. If biodiversity is well managed and conserved, it will act as a barrier against the spill-over of infectious diseases.
\end{abstract}

Keywords: COVID-19, biodiversity, pandemic, epidemic

Dear Editor,

If we go back in the history, it is clear that the epidemics and pandemics have caused a big loss to the human world and affected the development, human health, economy of the nation and well-being of human civilization, all of which have far-reaching consequences. In the recent past, conservation of biodiversity has been seen by linking it to the epidemics and pandemics. Although epidemics and pandemics have been observed since time immemorial, but their sources of origin could not be recognized at the time of occurrence and has always been identified later when the outbreak of diseases had impacted the human world. However, with the advancement of scientific field, it became clear that there is some link between the biodiversity and spread of outbreaks of epidemics and pandemics. Interestingly, preservation of biodiversity has been recognized as an important step to control the disease outbreaks since the last one year.

Biodiversity contributes towards keeping the ecosystems healthy, which provides ecosystem goods and services to human beings, and boosts economy as well as mitigating the negative impacts of climate change. Since the outbreak of diseases has been observed mainly from the animals, biodiversity also plays an important role in preventing the spread of diseases by providing them with a natural shelter. Increased human interface with animals, livestock farming, illegal hunting, use of bush-meat and wildlife trade activities are some of the causes identified behind the spread of most of the infectious diseases, which are caused by zoonotic pathogens. Land-use changes, as a consequence of expansion of agricultural fields, expansion of human helmets, extraction of biological resources and linear infrastructure development is also one of the key drivers behind the infectious disease emergence. The majority of all human infectious diseases and pandemics have originated through the cross-species transmission of microorganisms from animals to humans, overwhelmingly in the Old World (Wolfe et al., 2007). Rapid increase in human population, human-induced changes in natural environment, communities' dependency on biological resources, changes in micro climate at local and regional level are some of the driving factors, which are causes behind the spill over of disease outbreaks.

Recently, an expert report of the Intergovernmental Science-Policy Platform on Biodiversity and Ecosystem Services (IPBES) highlights that there is a close nexus between the global health pandemics and the biodiversity and climate crisis. Further, the report indicates that COVID-19 crisis, and the previous global health pandemics all have one thing in common: Their emergence is entirely driven by human activities (IPBES, 2020). The United Nation's Food and Agriculture Organization's report titled 'World Livestock 2013: Changing disease landscapes' stated that $70 \%$ of the new diseases that have emerged in human beings in recent decades are of animal original. This percentage show the extent to which human health is closely tied to livestock and animal health. The findings of most of the studies indicated that most 
of the pandemics were animal-borne and wild originated, but finally, were the part of the human world.

It has been estimated that nearly $60 \%$ emerging infectious diseases globally are zoonoses, and up to $75 \%$ of new or emerging infectious diseases are zoonotic in origin, which are increasing significantly over time (Jones et al., 2008). Besides, it has also been estimated that zoonoses are responsible for 2.5 billion cases of human illness and 2.7 million human deaths worldwide each year due to the top 56 zoonoses (Gebreyes et al., 2014). A study reported that zoonotic diseases originating in animals and those caused by pathogens transmitted by vector hosts were responsible for the majority of outbreaks (Smith et al., 2014). Of the 1,415 species of infectious organism known to be pathogenic to humans, 868 (61\%) are zoonotic and 175 pathogenic species are associated with diseases considered to be 'emerging', of which 132 (75\%) are zoonotic (Taylor et al., 2001).

Cases of epidemics and pandemics:

* The Black Death: In the $14^{\text {th }}$ century, the Black Death emerged as a devastating epidemic which took the lives of over 50 million people. This epidemic was considered as one of the most lethal in the history of humankind. The epidemic was reported to be caused by the bacteria Yersinia pestis, which is found in small mammals.

* Rabies: Rabies is a viral form of zoonotic disease caused by a virus from the Rhabdoviridae family. Rabies causes thousands of deaths every year in over 100 countries. It has been estimated that about 59,000 people die from rabies every year in the world, mainly in Asia and Africa.

* Avian Flu: Avian flu is also a zoonoses caused by Influenza, a virus subtypes. It is a type of flu that originally affects birds, but some strains can infect different mammals that are in contact with infected birds, including humans.

* Spanish Flu (1918-1919): Caused by H1N1 influenza virus, Spanish flu emerged as one of the biggest pandemic in the world, which killed about 50 million people. Even though it has been assumed that this lethal virus has genes of avian origin, however, actual source of origin of the virus remains unknown, and any consensus has not been reached so far.

* Asian Flu (1957-1958): Firstly, reported from East Asia from the H2N2 influenza virus, Asian flu killed about 2 million people. It was considered that it originated from the strains of avian influenza (wild ducks) amalgamating with the human strain.

* Hong Kong Flu (1968-1970): The virus was reported to be an H3N2 subtype resulting from the recombination of avian and human influenza virus. The pandemic killed about one million people. In 1990s, a closely related H3N2 virus was also isolated from pigs, for which it was suspected that the human H3N2 virus moved to the pigs.

* Human Immunodeficiency Virus (HIV): Firstly, identified in 1980s, HIV has been known to cause the chronic disease named Acquired Immunodeficiency Syndrome (AIDS). The disease killed about 32 million people around the world. It is believed that the HIV crossed from chimps to humans in the 1920s in the Democratic Republic of Congo.

- Severe Acute Respiratory Syndrome (SARS) (2002-2003): Having emerged first from the China in 2002, SARS is a viral respiratory disease caused by a SARS-associated coronavirus. It had killed about 750 people. As far the origin of virus is concerned various workers have given different views, however, all the hypothesis was related to the animals. Coronavirus that was phylogenetically related to SARS-CoV-2 were found in rhinolophus bats in South Asian countries including China, Japan, Cambodia, and Thailand (Zhou et al., 2020).

* Avian Influenza (2003-2004): Commonly known as Bird Flu, the outbreak of Avian influenza was first started during 2003. Virus is known to occur in wild and domestic birds and normally not infect the humans. H5N1 strain of bird flu killed more than 400 people, mainly in Southeast Asia since its emergence. It first ravaged poultry farms in Hong Kong, before being transmitted to humans.

* Swine Flu (2009-2010): First exposed in Mexico and the United States in the year 2009, and as per the report of WHO, it about 18500 people (lab-confirmed cases). However, the US Centre for Disease and Control Prevention (CDC) estimated that 150,000 to 575,000 people died from (H1N1) pandemic virus infection in the first year of the outbreak.

Studies conducted in the recent past authenticates that the outbreak of various diseases such as SARS and Bird's Influenza, which spread from the animals to humans have increased in the past few decades (Jones et al., 2008; Smith et al., 2014). A study pointed out that such spread of diseases is the result of increased contact between human, wildlife and livestock (Tollefson, 2020). The outbreaks of Ebola, Zika, Nipah, and COVID-19 viruses has make it clear that there is a need to study the source of pathogen transmission, especially in context of biodiversity.

The COVID-19 pandemic has clearly indicated the importance of environmental health. Minimizing human interface with wild animals, understanding the nature, monitoring of the illegal wildlife trade and conserving natural habitats, would strengthen our efforts in future for preventing pandemics and epidemic. Micro-ogranisms have not always found harming the human beings, in fact animals are known as the host in serving microorganisms, some of which are beneficial as well. Besides, microorganisms have an important role in maintaining natural ecosystems, and therefore, if biodiversity is well managed and conserved, which serves as the natural habitat for these microorganisms, it will act as a barrier against the spill-over of infectious diseases.

Author contributions: All co-authors have involved in all stages of this study while preparing the final version. They all agree with the results and conclusions.

Funding: No external funding is received for this article.

Declaration of interest: The authors declare that they have no competing interests.

Ethics approval and consent to participate: Not applicable. 
Availability of data and materials: All data generated or analyzed during this study are available for sharing when appropriate request is directed to corresponding author.

\section{REFERENCES}

Gebreyes, W. A., Dupouy-Camet, J., Newport, M. J., Oliveira, C. J. B., et al. (2014). The global one health paradigm: Challenges and opportunities for tackling infectious diseases at the human, animal, and environment interface in low-resource settings. PLoS Neglected Tropical Disease, 8(11), e3257.https://doi.org/10.1371/journal.pntd.0003257

IPBES. (2020). Workshop report on biodiversity and pandemics of the intergovernmental platform on biodiversity and ecosystem services. Available at https://ipbes.net/sites/ default/files/2020-12/IPBES\%20Workshop\%20on\% 20Biodiversity\%20and\%20Pandemics\%20Report_0.pdf

Jones, K. E., Patel, N. G., Levy, M. A., Storeygard, A., et al. (2008). Global trends in emerging infectious diseases. Nature, 451, 990-993. https://doi.org/10.1038/nature06536
Smith, K. F., Goldberg, M., Rosenthal, S., Carlson, L., et al. (2014). Global rise in human infectious disease outbreaks. Journal of the Royal Society Interface, 11(101), 20140950. https://doi.org/10.1098/rsif.2014.0950

Taylor, L. H., Latham, S. M. and Woolhouse, M. E. (2001). Risk factors for human disease emergence. Philosophical Transactions of the Royal Society of London. Series B, Biological sciences, 356(1411), 983-989. http://doi.org/10.1098/rstb.2001.0888

Tollefson, J. (2020). Why deforestation and extinctions make pandemics more likely. Nature, 584, 175-176. https://doi.org/10.1038/d41586-020-02341-1

Wolfe, N. D., Dunavan, C. P. and Diamond, J. (2007). Origins of major human infectious diseases. Nature, 447, 279-283. https://doi.org/10.1038/nature05775

Zhou, P., Yang, X.-L., Wang, X.-G., Hu, B., et al. (2020). A pneumonia outbreak associated with a new coronavirus of probable bat origin. Nature, 579, 270-273. https://doi.org/10.1038/s41586-020-2012-7 